\title{
Inosine Protects Against the Development of Diabetes in Multiple-Low-Dose Streptozotocin and Nonobese Diabetic Mouse Models of Type 1 Diabetes
}

\author{
Jon G Mabley, ${ }^{1}$ Alex Rabinovitch, ${ }^{2}$ Wilma Suarez-Pinzon, ${ }^{2}$ György Haskó, ${ }^{3}$ Pál Pacher, ${ }^{1}$ \\ Robert Power, ${ }^{4}$ Gary Southan, $^{1}$ Andrew Salzman, ${ }^{1}$ And Csaba Szabó ${ }^{1,3}$
}

\begin{abstract}
Inosine, a naturally occurring purine, was long considered to be an inactive metabolite of adenosine. However, recently inosine has been shown to be an immunomodulator and anti-inflammatory agent. The aim of this study was to determine whether inosine influences anti-inflammatory effects and affects the development of type 1 diabetes in murine models. Type 1 diabetes was induced either chemically by streptozotocin or genetically using the nonobese diabetic mouse (NOD) model. Mice were treated with inosine (100 or $200 \mathrm{mg} \mathrm{kg}^{-1} \mathrm{~d}^{-1}$ ) and diabetes incidence was monitored. The effect of inosine on pancreas immune cell infiltration, oxidative stress, and cytokine profile also was determined. For the transplantation model islets were placed under the renal capsule of NOD mice and inosine $\left(200 \mathrm{mg} \mathrm{kg}^{-1} \mathrm{~d}^{-1}\right)$ treatment started the day of islet transplantation. Graft rejection was diagnosed by return of hyperglycemia accompanied by glucosuria and ketonuria. Inosine reduced the incidence of diabetes in both streptozotocin-induced diabetes and spontaneous diabetes in NOD mice. Inosine decreased pancreatic leukocyte infiltration and oxidative stress in addition to switching the cytokine profile from a Th1 to a Th2 profile. Inosine prolonged pancreatic islet graft survival, increased the number of surviving $\beta$ cells, and reduced the number of infiltrating leukocytes. Inosine protects against both the development of diabetes and against the rejection of transplanted islets. The purine exerts anti-inflammatory effects in the pancreas, which is its likely mode of action. The use of inosine should be considered as a potential preventative therapy in humans susceptible to developing Type 1 diabetes and as a possible antirejection therapy for islet transplant recipients.
\end{abstract}

\section{INTRODUCTION}

It is well recognized that certain naturally occurring purines can exert powerful modulatory effects on the immune system. The nucleoside adenosine is the best characterized of these purines and has been shown to affect almost all aspects of an immune response (1-3). Adenosine and its analogs can affect the development of a variety of inflammatory diseases including endotoxic shock (4), rheumatoid arthritis (5), pleural inflammation (6), nephritis (7), uveitis (8), and colitis (9). Adenosine's effects are partly mediated by the inhibition of deleterious immune-mediated processes, including the release of proinflammatory cytokines and free radicals (10). Inosine is a naturally occurring purine, formed from the breakdown of adenosine by adenosine deaminase (11). Although inosine was widely believed to be inert, we have demonstrated that inosine inhibits the release of proinflammatory cytokines and chemokines by activated murine macrophages (12), and that this compound exerts powerful in vivo anti-inflammatory effects in murine endotoxic shock $(12,13)$, colitis $(9)$, septic shock (14), and severe lung inflammation (15). Inosine also has anti-inflammatory effects on human cells in vitro, reducing tumor necrosis factor- $\alpha$ $(\mathrm{TNF}-\alpha)$ and interleukin (IL)-1 $\beta$ production by monocytes and epithelial cells in response to lipopolysaccharide treatment, as well as inhibiting superoxide radical production by activated human neutrophils (16).

Type 1 diabetes is a disease characterized by the specific destruction of insulin-producing $\beta$ cells in the pancreatic islets of Langerhans by the immune system (17). The islet is invaded by immune cells, particularly macrophages and $\mathrm{T}$ cells, and these cells are cytotoxic to islet $\beta$ cells, in part by generating cytokines and free radicals (18). It has been proposed that the insulitis lesion is $\beta$-cell destructive when Th1 cytokines (IL-12, interferon (IFN)- $\gamma$, IL-1, and TNF- $\alpha$ ) produced by islet infiltrating macrophages and T cells dominate over Th2 cytokines (IL-4, IL-10) (19).

There are 2 murine models of autoimmune diabetes: the multiple-low-dose streptozotocin (MLDS) model and the spontaneous nonobese diabetic (NOD) mouse model. The MLDS model of diabetes is characterized by a progressive hyperglycemia and insulitis similar to that observed in human subjects with recent-onset type 1 diabetes $(20,21)$. The NOD mouse model also shares clinical, serological, and histoimmunological features with human type 1 diabetes (22). Both models have been used extensively to study preventative therapies for type 1 diabetes $(22,23)$. A variety of procedures and therapies that delete, suppress, or

'Inotek Pharmaceuticals Corp, Beverly, MA; ${ }^{2}$ Department of Medicine, University of Alberta, Edmonton, Alberta, Canada; ${ }^{3}$ Department of Surgery, New Jersey Medical School, Newark, NJ; and ${ }^{4}$ Department of Laboratory Medicine, University of Alberta, Edmonton, Alberta, Canada. 
modulate functions of the immune system cells can block the autoimmune response against islet $\beta$ cells and prevent $\beta$-cell destruction and may even reverse established diabetes in the NOD mouse $(24,25)$. In view of the finding that inosine is a potent immunomodulating agent $(9,12-16)$, the present study was designed to test the potential effects of inosine in murine models of type 1 diabetes.

\section{MATERIALS AND METHODS}

\section{Materials}

Reagents were obtained from the following sources. Streptozotocin and sodium citrate were obtained from Sigma (St. Louis, MO, USA). BALB/c mice and NOD mice were purchased from Taconic (Germantown, NY, USA). Insulin ELISA kits were obtained from Alpco (Windham, NH, USA) and insulin radioimmunoassay kits were from Linco Research (St Charles, MO, USA). Urine glucose Tes-Tape was from Eli Lilly (Toronto, ON, Canada), and a One-Touch II hospital blood glucose meter was from Lifescan (Johnson \& Johnson company, Milpitas, CA, USA). Cytokine ELISA kits were from R\&D Systems (Minneapolis, MN, USA).

\section{Induction of Diabetes}

All animal experiments were carried out in accordance with the guidelines published by the NIH in Principles of Laboratory Animal Care (NIH publication no. 85-23, revised 1985) and the guidelines of the Canadian Council on Animal Care. Male BALB/c mice were treated with streptozotocin $(40 \mathrm{mg} / \mathrm{kg}$ dissolved in citrate buffer, $\mathrm{pH} 4.5$ ) or vehicle (citrate buffer) intraperitoneally for 5 consecutive days. Mice were treated everyday starting on day 1 with either inosine $\left(30,100\right.$, or $\left.200 \mathrm{mg} \mathrm{kg}^{-1} \mathrm{~d}^{-1}\right)$ or vehicle (water) orally by gavage. Blood glucose was measured on days 1, 7, 14, and 21 from blood obtained from the tail vein. Hyperglycemia was defined as a nonfasting blood glucose level $\geq 11 \mathrm{mmol} / \mathrm{L}$. Cumulative incidence of diabetes was calculated as a percentage of hyperglycemic mice at each time point. Biopsies of pancreas were removed on day 21 for biochemical and cytokine assays.

Female NOD mice were purchased at $4 \mathrm{wk}$ of age and allowed to acclimatize to our animal facility for $1 \mathrm{wk}$ prior to daily treatment with inosine (200 mg kg-1 $\mathrm{d}^{-1}$, orally) commencing at $5 \mathrm{wk}$ of age. In the 1st study, spontaneous diabetes incidence was monitored until $30 \mathrm{wk}$ of age. Urine glucose levels were checked daily and a mouse was defined as diabetic following $3 \mathrm{~d}$ of glucosuria and a blood glucose level of $\geq 11 \mathrm{mmol} / \mathrm{L}$. In the 2 nd study, female NOD mice were treated in the same way, and when the mice reached 18 wk of age, pancreas biopsies were taken from normoglycemic NOD mice for biochemical, cytokine, and histological analysis.

\section{Determination of Pancreatic Insulin, Myeloperoxidase, Malondialdehyde, and Cytokines}

Insulin contents in pancreata of BALB/c mice were determined from a pancreas biopsy, which was homogenized in acidified ethanol (75\% ethanol, 1.5\% $12 \mathrm{~mol} / \mathrm{L} \mathrm{HCl}$, and $23.5 \% \mathrm{H}_{2} \mathrm{O}$ ), and then incubated for $72 \mathrm{~h}$ at $4{ }^{\circ} \mathrm{C}$ and centrifuged. Care was taken to remove biopsies from the same location of the pancreas (body) to avoid differences between the regions of the pancreas in regards to insulin content. The insulin content of the supernatant was determined using an ELISA kit (Alpco). Pancreatic insulin content was expressed as ng insulin/mg protein, which was determined by the Bradford assay (26). For the pancreatic insulin content of NOD mice, a $90 \%$ portion of the pancreas (the other $10 \%$ going toward histological study) was removed, weighed, homogenized in acidified ethanol, and insulin was measured using a radioimmunoassay kit (Linco Research) and expressed as ng/mg pancreas.

For assay of myeloperoxidase (MPO) activity in pancreas, the pancreas biopsy was homogenized in $0.5 \%$ hexadecyltrimethylammonium bromide dissolved in $10 \mathrm{mmol} / \mathrm{L} \mathrm{3-(N-}$ morpholino)propanesulfonic acid and centrifuged at $15000 \times g$ for $40 \mathrm{~min}$. The suspension was then sonicated 3 times for $30 \mathrm{~s}$. An aliquot of supernatant was mixed with a solution of 1.6 mmol/L tetra-methyl-benzidine and $1 \mathrm{mmol} / \mathrm{L}$ hydrogen peroxide. MPO activity was measured spectrophotometrically as the change in absorbance at $650 \mathrm{~nm}$, using a Spectramax microplate reader (Molecular Devices, Sunnyvale, CA, USA) (14). Results are expressed as milliunits of MPO activity per mg protein.

Malondialdehyde (MDA) content in the pancreas was determined from a pancreatic biopsy homogenized in $1.15 \% \mathrm{KCl}$ buffer. Homogenate $(200 \mu \mathrm{L})$ was added to a reaction mixture consisting of $1.5 \mathrm{~mL} 0.8 \%$ thiobarbituric acid, $200 \mu \mathrm{L} 8.1 \%$ sodium dodecyl sulfate, $1.5 \mathrm{~mL} 20 \%$ acetic acid ( $\mathrm{pH} 3.5$ ), and $600 \mu \mathrm{L}$ distilled $\mathrm{H}_{2} \mathrm{O}$. The mixture was incubated at $90{ }^{\circ} \mathrm{C}$ for $45 \mathrm{~min}$. After cooling to room temperature, the sample was cleared by centrifugation $(10000 \times g, 10 \mathrm{~min})$ and absorbance measured at $532 \mathrm{~nm}$, using 1,1,3,3-tetramethoxypropane as an external standard (14). Results are expressed as pmol MDA/mg protein.

Cytokines expressed in pancreas were determined from a pancreas biopsy snap frozen in liquid nitrogen. The biopsies were homogenized in $700 \mu \mathrm{L}$ of a Tris $\mathrm{HCl}$ buffer containing protease inhibitors (27), centrifuged for $30 \mathrm{~min}$, and then the supernatant was removed and frozen at $-80{ }^{\circ} \mathrm{C}$ until assay. Cytokine contents in pancreas were determined using specific ELISA kits (R\&D Systems) and expressed as pg cytokine protein/mg protein.

\section{Histological Studies}

A portion $(10 \%)$ of pancreas from NOD mice was fixed in $10 \%$ buffered formalin, embedded in paraffin, sectioned at $4.5 \mu \mathrm{m}$, and then stained with an anti-insulin antibody (Dako, Carpinteria, CA, USA) using an immunoperoxidase technique and counterstained with hematoxylin. Coded slides were examined by light microscopy. Islet infiltration (insulitis) was graded 0 to 3 , according to the extent of intra-islet infiltration by leucocytes: 0 , none; 1 , $<10 \% ; 2,10 \%$ to $50 \%$; and 3, $>50 \%$ infiltration. A mean insulitis score was calculated for each pancreas by dividing the sum of the insulitis scores for individual islets by the number of islets examined. Islet grafts transplanted into NOD mice were fixed, embedded, and sectioned, as above, then stained with hematoxylin and eosin and examined by light microscopy.

\section{Islet Transplantation Studies}

Islets were isolated from 4-wk-old female NOD mice by collagenase digestion of the pancreas and Ficoll density gradient centrifugation 
and then hand picked (28). A total of 500 freshly isolated islets were transplanted under the left renal capsule in each diabetic NOD mouse, according to a previously described procedure (29). The islet recipient mice were given either vehicle (water) or inosine (200 $\left.\mathrm{mg} \mathrm{kg}^{-1} \mathrm{~d}^{-1}\right)$ by gavage beginning the day of islet transplantation. Transplantation was considered successful if the nonfasting blood glucose returned to normal $(<7 \mathrm{mmol} / \mathrm{L})$ and remained normal for the 1 st $4 \mathrm{~d}$ after transplantation. Urine was monitored daily after transplantation and if glucosuria and ketonuria appeared, then tail vein blood glucose was measured. Graft rejection was diagnosed by return of hyperglycemia (blood glucose $\geq 11 \mathrm{mmol} / \mathrm{L}$ ) accompanied by glucosuria and ketonuria on 2 consecutive days.

\section{Immunohistochemical Studies}

The islet grafts were removed and cut into small pieces with fine scissors, disrupted by syringe injection through progressively narrower gauge needles, and dissociated into single cells by incubation in $\mathrm{Ca}^{2+} / \mathrm{Mg}^{2+}$-free phosphate-buffered saline with $0.2 \mathrm{mg} / \mathrm{mL}$ EDTA. Leukocytes and islet $\beta$ cells isolated from the grafts were identified by using immunohistochemical methods, as previously described (30). Briefly, cells were fixed in $4 \%$ paraformaldehyde and placed on glass slides coated with 3-aminopropyltriethoxysilane. Primary antibodies for cell staining were a guinea pig anti-insulin (Dako) or control antibody diluted 1:20 in phosphate-buffered saline, a rat monoclonal antibody (Ly-5/ T200; Cedarlane, Hornby, ON, Canada) to mouse total leukocytes $\left(\mathrm{CD} 45^{+}\right)$or rat IgG control antibody. Secondary antibodies were biotinylated goat anti-guinea pig Ig and biotinylated goat anti-rat mouse-absorbed IgG. Next, cells were incubated with steptavidin-alkaline phosphatase conjugate and then with alkaline phosphatase Fast-blue chromogen, and the slides were sealed for microscopic examination.

\section{Statistical Analyses}

Data are presented as means \pm SE. Statistical analysis was performed using the ANOVA with Bonferroni's correction, Fisher's exact test, or Student's $t$-test as appropriate; $P<0.05$ was considered significant.

\section{RESULTS}

\section{Inosine Protects Against MLDS-induced Hyperglycemia and Diabetes}

MLDS treatment induced a progressive hyperglycemia over a 21-d period, with a corresponding increase in diabetes incidence (blood glucose $\geq 11 \mathrm{mmol} / \mathrm{L}$ ) in BALB/c mice (Figure 1A and 1B). Inosine at both 100 and $200 \mathrm{mg} \mathrm{kg}^{-1} \mathrm{~d}^{-1}$ significantly reduced the rise in mean blood glucose level at $21 \mathrm{~d}$ (see Figure 1A). Furthermore, the incidence of diabetes on day 21 decreased from $80 \%$ to $30 \%$ and $13 \%$ in response to 100 and $200 \mathrm{mg} \mathrm{kg}^{-1} \mathrm{~d}^{-1}$ inosine, respectively (see Figure 1B). A lower dose of inosine $30 \mathrm{mg}$ $\mathrm{kg}^{-1} \mathrm{~d}^{-1}$ had no effect on the MLDS-mediated rise in blood glucose levels (251 \pm 17 compared with $231 \pm 16 \mathrm{mg} / \mathrm{dL}$ for vehicle and inosine treatment respectively on day 21), increased incidence of diabetes ( $82 \%$ compared with $73 \%$ on day 21$)$, and decreased pan-
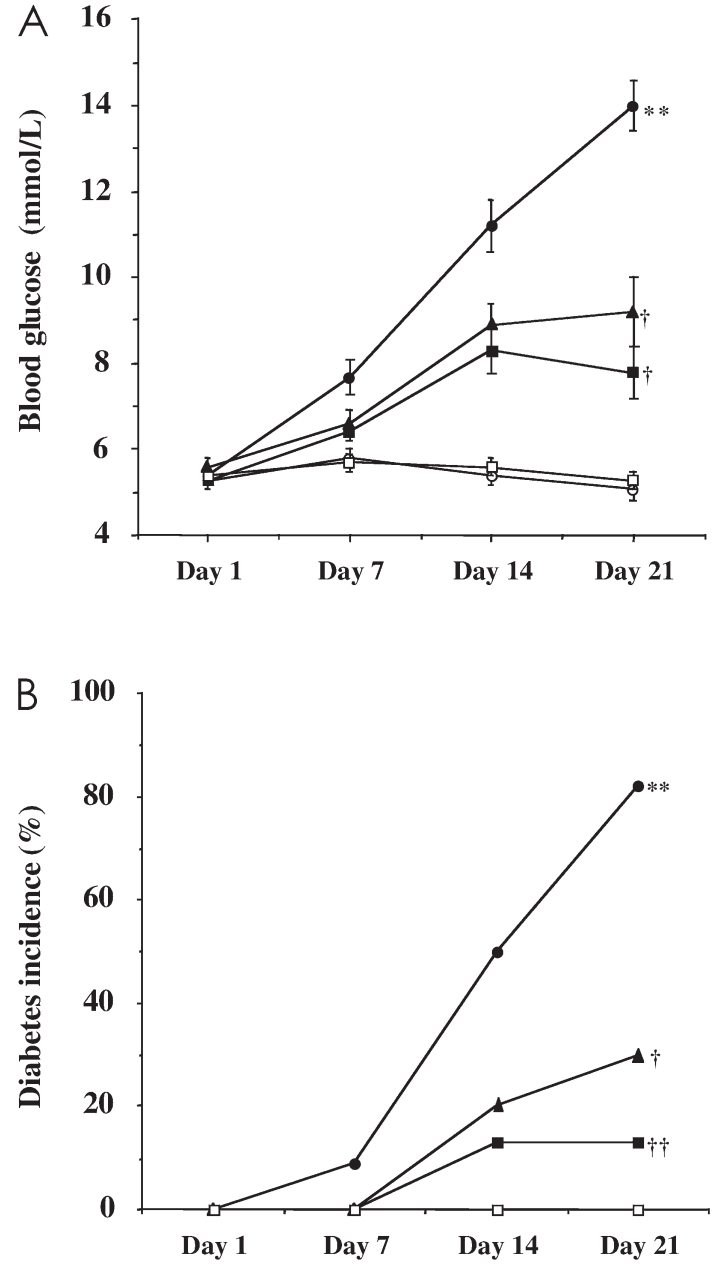

Figure 1. Daily treatment with inosine (100 or $200 \mathrm{mg} \mathrm{kg}^{-1} \mathrm{~d}^{-1}$ ) for $21 \mathrm{~d}$ decreases hyperglycemia (A) and incidence of diabetes (B) following MLDS treatment of BALB/C mice on days 1 to 5 . Diabetes incidence is expressed as a cumulative percentage of mice with a blood glucose $\geq 11 \mathrm{mmol} / \mathrm{L}$. Mice were either untreated (O), given inosine $200 \mathrm{mg} \mathrm{kg}^{-1} \mathrm{~d}^{-1}$ alone $(\square)$, or treated with streptozotocin in combination with vehi-

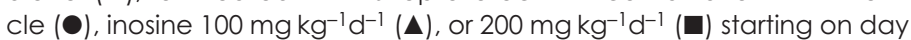
1. Results are means \pm SE for $n=20$ mice in 2 separate experiments with 10 mice per experimental group. ${ }^{* *} P<0.01$ compared with vehicletreated mice; $\uparrow P<0.05 ; \dagger \uparrow P<0.01$ compared with MLDS-treated mice.

creas insulin content (16 \pm 3 compared with $18 \pm 3 \mathrm{ng}$ insulin/mg protein). Inosine alone had no effect on blood glucose (see Figure 1A) or diabetes incidence (see Figure 1B).

Inosine Protects the Pancreas from Loss of $\beta$ cells, Leukocyte Infiltration, and Lipid Peroxidation Following MLDS Treatment

MLDS treatment significantly decreased the pancreatic insulin content in BALB/c mice on day 21, and this was significantly reversed by inosine treatment (Figure $2 \mathrm{~A}$ ). MPO activity was found to be 3-fold higher in the pancreas following MLDS treatment (see Figure 2B), indicative of an invasion of the pancreatic tissue by polymorphonuclear leukocytes and monocytes. Inosine treatment dose-dependently reduced pancreatic MPO activity (see 
A

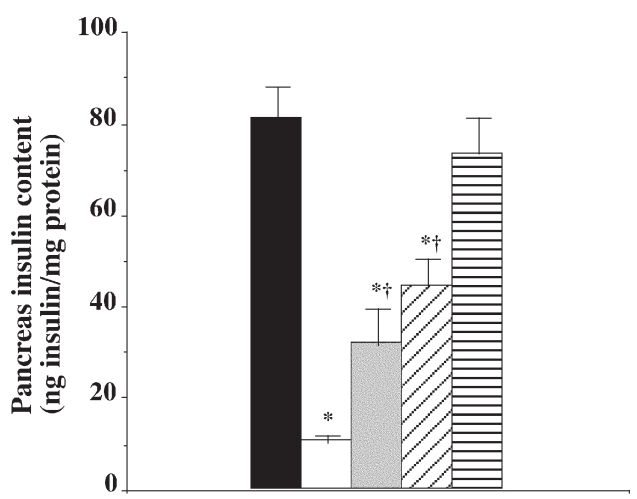

B

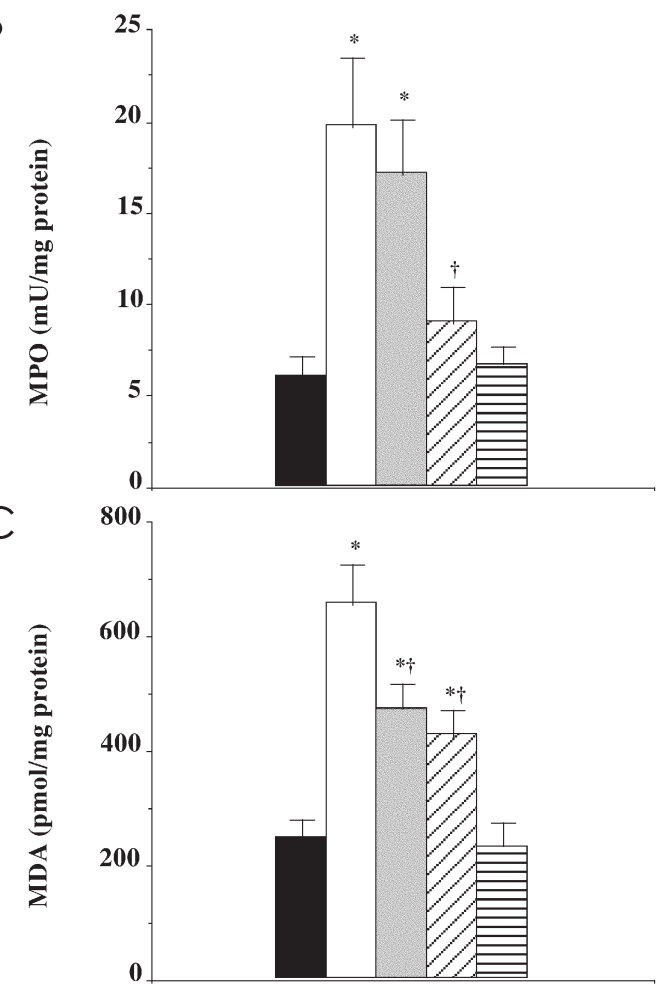

Figure 2. Inosine treatment attenuates the effects of MLDS treatment on pancreatic insulin content (A), MPO activity (B), and MDA content (C) in BALB/C mice. Mice were either untreated (四), given inosine $200 \mathrm{mg}$ $\mathrm{kg}^{-1} \mathrm{~d}^{-1}$ alone $(\boldsymbol{\Xi})$, or treated with streptozotocin in combination with vehicle ( $\square$ ), inosine $100 \mathrm{mg} \mathrm{kg}^{-1} \mathrm{~d}^{-1}(\square)$, or $200 \mathrm{mg} \mathrm{kg}^{-1} \mathrm{~d}^{-1}$ (■) starting on day 1 . Results are means \pm SE for $n=10$ to 20 mice in 2 separate experiments with 10 mice per experimental group. ${ }^{*} P<0.05$ compared with vehicle-treated mice; $\uparrow P<0.05$ compared with MLDS-treated mice.

Figure 2B). MDA formation was used to quantify lipid peroxidation in the pancreas, a measure of oxidative stress. MDA was found to be elevated 3-fold by MLDS treatment and inosine attenuated this effect (see Figure 2C).

\section{Effects of MLDS and Inosine on Pancreatic Cytokines}

MLDS treatment increased the pancreatic contents of IL-12 (p40), TNF- $\alpha$ and IFN- $\gamma$ (Th1 cytokines), and IL-1 in BALB/c mice on day 21 (Figure 3A). Inosine treatment prevented the increase in both IL-12 (p40) and IFN- $\gamma$ levels following MLDS treatment and partially attenuated the rise in TNF- $\alpha$ levels (see Figure 3A). However, inosine had no effect on the MLDS-induced increase in pancreatic IL-1 (see Figure 3A). MLDS treatment had no effect on the pancreatic levels of the Th2 cytokines, IL- 4 and IL-10 (see Figure 3B). However, mice treated with MLDS plus inosine had a significantly increased pancreatic IL-4 content (see Figure 3B) and a trend toward an increased IL-10 content. However, this latter effect was not statistically significant $(P=0.07)$.

\section{Inosine Reduces the Incidence of Diabetes, Insulitis, and $\beta$-cell Loss in NOD Mice}

Female NOD mice were treated daily from the age of $5 \mathrm{wk}$ with either inosine or vehicle (water). Inosine treatment decreased diabetes incidence, with only $22 \%$ of mice that were diabetic at $20 \mathrm{wk}$ of age compared with $66 \%$ in the vehicle-treated group $(P=0.018)$,
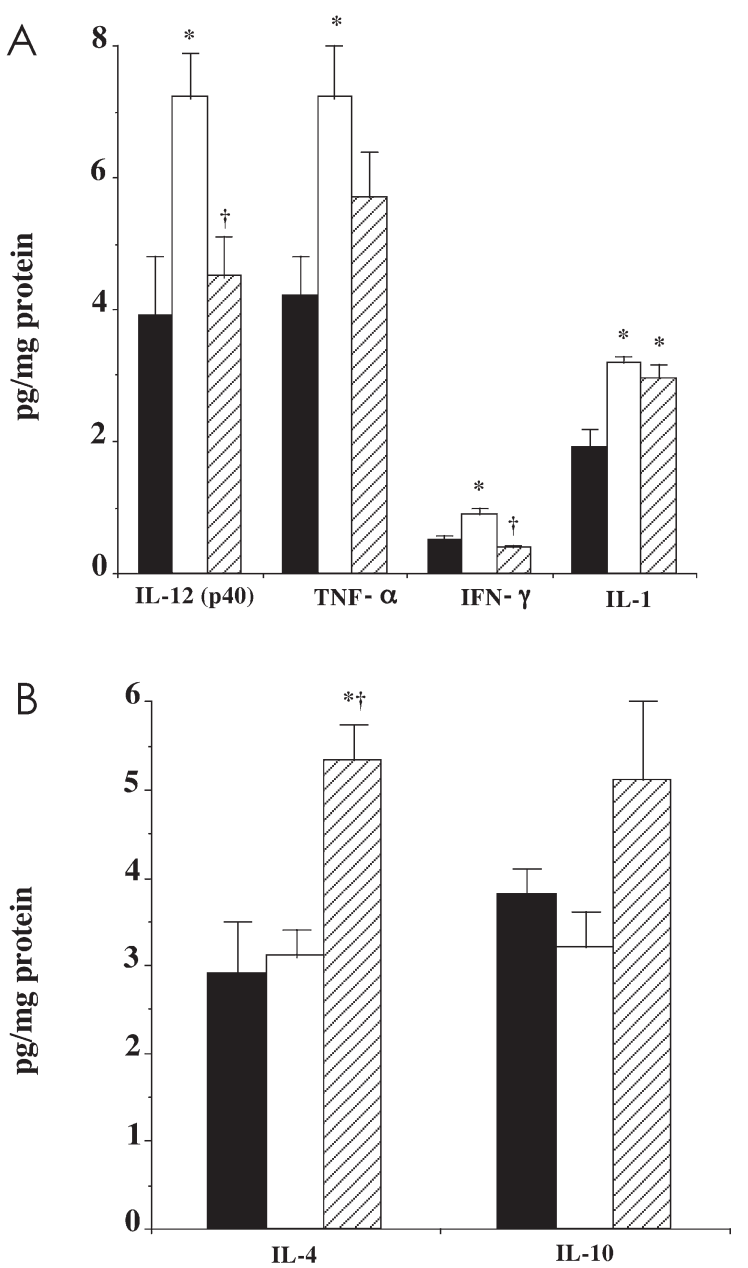

Figure 3. Inosine (200 $\left.\mathrm{mg} \mathrm{kg}^{-1} \mathrm{~d}^{-1}\right)$ prevents the MLDS-induced increases in IL-12 (p40) and IFN- $\gamma$ in pancreata of BALB/C mice, while increasing the level of IL-4. Mice were untreated ( $\mathbf{\square})$ or treated with streptozotocin in combination with either vehicle ( $\square$ ) or inosine $200 \mathrm{mg} \mathrm{kg}^{-1} \mathrm{~d}^{-1}(\square)$ starting on day 1 . Results are means \pm SE ( $n=10$ mice per group). ${ }^{*} P<0.05$ compared with vehicle-treated mice; $\uparrow P<0.05$ compared with MLDStreated mice. 


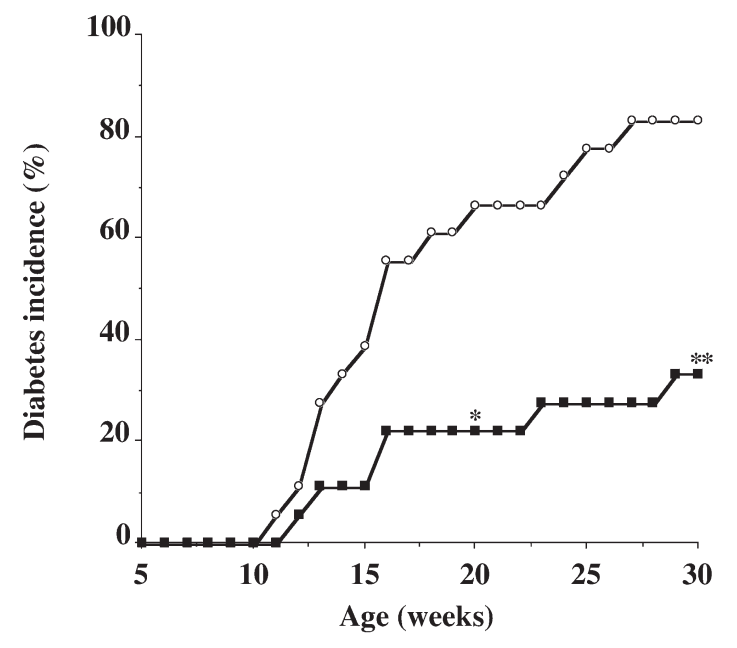

Figure 4. Daily inosine (200 $\mathrm{mg} \mathrm{kg}^{-1} \mathrm{~d}^{-1}$ orally) ( $\mathbf{\square}$ ) treatment starting at 5 wk of age decreases the incidence of diabetes as compared with vehicle-treated (O) female NOD mice. ${ }^{*} P=0.018 ;{ }^{*} P=0.006$ compared with vehicle-treated mice at 20 and 30 wk of age, respectively ( $n=18$ mice in each group).

and this protection continued until $30 \mathrm{wk}$ when $83 \%$ of the vehicle-treated mice were diabetic compared with $33 \%$ of the inosine-treated mice $(P=0.006)$ (Figure $4 \mathrm{~A})$. In addition, inosine treatment reduced islet leukocyte infiltration (Figure $5 \mathrm{~A}$ to $5 \mathrm{C}$ ), and this effect was reflected in the insulitis score, which was 3-fold lower in the inosine-treated mice compared with vehicle-treated mice (see Figure 5D). The number of viable $\beta$ cells as reflected by pancreatic insulin content, also was significantly higher in inosine-treated NOD mice than in vehicle-treated NOD mice (see Figure 5D).

\section{Pancreatic Cytokines and Chemokines in NOD Mice}

Pancreatic contents of the Th1 cytokines, IL-12 (p40) and TNF- $\alpha$ were significantly lower in NOD mice treated with inosine than in vehicle-treated NOD mice (Figure 6A). In addition, the diabetesassociated increase in the pancreatic content of the chemokine, MIP-1 $\alpha$, was significantly attenuated by inosine (Figure 6A). There was no difference in the pancreatic content of the Th2 cytokine, IL- 4 (Figure 6B), and there was a trend $(P=0.06$, not significant) toward an increased IL-10 content in the pancreata of diabetic NOD mice treated with inosine (Figure 6B).

\section{Islet Transplantation Study}

Transplantation of syngeneic islets into diabetic NOD mice was used to assess the potential of inosine to block a strong established autoimmune response. In the vehicle-treated mice, diabetes recurred in $100 \%$ of the islet-grafted mice by day 14 whereas inosine treatment $\left(200 \mathrm{mg} \mathrm{kg}^{-1} \mathrm{~d}^{-1}\right.$ ) prolonged the survival of the grafts and $50 \%$ of the mice remained normoglycemic at day 70 (Figure 7A). Insulin content of the islet graft was significantly higher in the inosine-treated mice as compared with both diabetic and normoglycemic vehicle-treated mice (see Figure 7B). Histological analysis of the grafts showed abundant leukocyte infiltration of these islets in vehicle-treated mice (Figure 8A) compared with inosine-treated mice (see Figure 8B). Immunohistochemical analyses of the grafts revealed that inosine treatment significantly decreased leukocyte infiltration into the grafts and reduced the loss of $\beta$ cells in the islet grafts (see Figure $8 \mathrm{C}$ ).

\section{DISCUSSION}

Our study demonstrates that inosine, a naturally occurring purine, protects against diabetes development in 2 animal models of type 1 diabetes, MLDS-induced diabetes in BALB/c mice and spontaneous diabetes in NOD mice. In addition, inosine was effective in preventing recurrence of autoimmune disease after islet transplantation in NOD mice. Previous reports revealed that inosine had marked anti-inflammatory effects, both in vitro and in vivo in acute inflammatory conditions $(9,12-16)$. Here we report on the effectiveness of inosine in protecting against the development of an autoimmune disease.

Our study in the MLDS-induced model of type 1 diabetes demonstrated that inosine dose-dependently protects against hyperglycemia and significantly reduces the incidence of diabetes. Doses of inosine under $100 \mathrm{mg}^{-1} \mathrm{~kg}^{-1} \mathrm{~d}^{-1}$ appear to be ineffective in protecting against MLDS-induced diabetes; similar to our previous published studies on colitis (9), endotoxic or septic shock $(12,14)$, and lung inflammation (15), inosine was effective only at dosages greater than $100 \mathrm{mg}^{-1} \mathrm{~kg}^{-1} \mathrm{~d}^{-1}$. Inosine reduced pancreatic infiltration by polymorphonuclear leukocytes and monocytes resulting in decreased pancreatic damage (lipid peroxidation) and a greater survival of $\beta$ cells. The effects of inosine appeared to be via a reduction of the pancreatic levels of the Th1 cytokines (IL-12, IFN- $\gamma$, TNF- $\alpha$ ). However, inosine failed to reduce pancreatic levels of IL-1. The cytokines IFN- $\gamma$, TNF- $\alpha$, and IL-1 all have been implicated in $\beta$-cell functional inhibition, destruction, and autoimmune diabetes (18,31). Also, IL-12 expression has been correlated with development of diabetes in the NOD mouse (32) and treatment of NOD mice with an IL-12 antagonist-suppressed diabetes development and decreased pancreatic expression of mRNA for IFN- $\gamma$ (33). In addition to decreasing pancreatic levels of Th1 cytokines (IL-12, IFN- $\gamma$, TNF- $\alpha$ ), inosine increased pancreatic levels of the Th2 cytokine, IL-4 in mice with MLDS-induced diabetes. Previous in vitro experiments have demonstrated inhibition of Th1 cytokines by inosine, without any increase in Th2 cytokine production from macrophages stimulated with lipopolysaccharide (12). In contrast, in endotoxemic mice inosine not only significantly reduced Th1 cytokine levels but also increased the levels of Th2 cytokines (12), suggesting that inosine's overall effect is a shift from a Th1- to a Th2-type cytokine profile.

A chemical form of inosine, inosine pranobex, has been reported previously to be partially protective against hyperglycemia in the MLDS-induced model of diabetes (34). Inosine pranobex was not as effective as inosine in protecting against MLDS-induced hyperglycemia and diabetes. However, inosine pranobex was administered at lower doses than inosine and given intraperitoneally rather than orally. Based on the current results, we believe that the protective effects of inosine pranobex (34) are related to the inosine component. Higher doses of inosine 

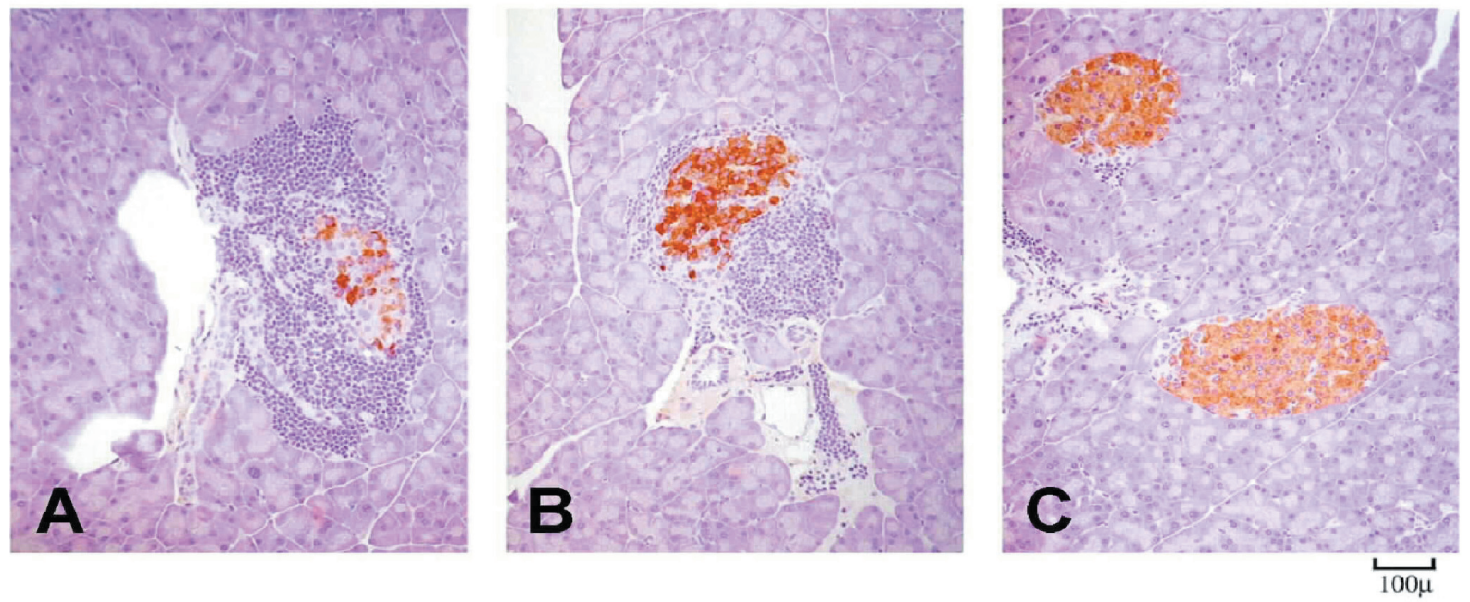

D

Insulitis score

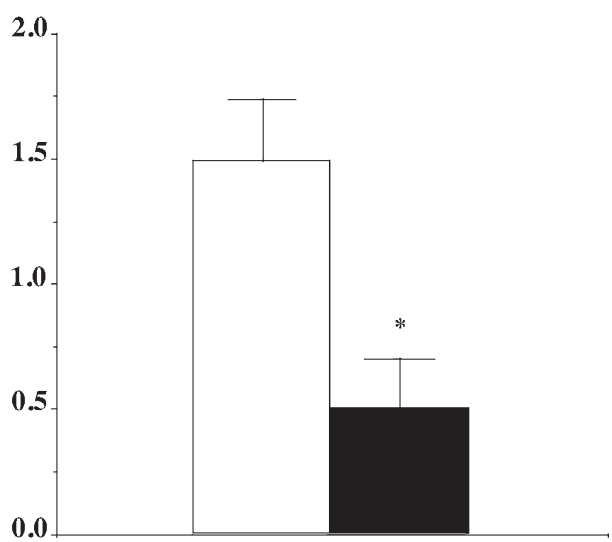

Insulin content

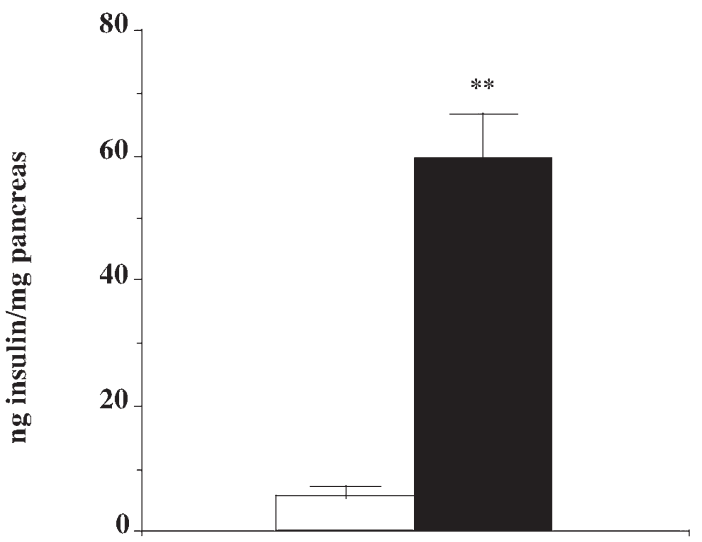

Figure 5. Histological analyses of pancreata from female NOD mice that were treated with vehicle and became diabetic (A), vehicle-treated and normoglycemic at $30 \mathrm{wk}$ of age (B), and inosine-treated and normoglycemic at $30 \mathrm{wk}$ of age (C). Leukocytic infiltration of islets is the most and insulincontaining $\beta$-cells (stained brown) are the least in pancreata of vehicle-treated diabetic mice (A), whereas leukocytic infiltration of islets is the least and $\beta$-cell mass is the most in islets of inosine-treated mice (C). Inosine ( $\mathbf{\square})$ significantly decreased the degree of insulitis (insulitis score) and prevented the loss of pancreatic insulin content in NOD mice normoglycemic at age 30 wk compared with vehicle-treated mice ( $\square$ ) (D). Results are means \pm $\mathrm{SE}(n=5$ to 7$) * P<0.05 ;{ }^{*} P<0.01$ compared with vehicle-treated mice.

pranobex in the previous study may have produced more of a protection against MLDS-induced diabetes. It is noteworthy that in some countries inosine pranobex has been approved for the treatment of humans with various inflammatory conditions including hepatitis and arthritis, and in humans, the doses of the compound range from $3 \mathrm{~g} / \mathrm{d}$ to $200 \mathrm{mg} \mathrm{kg}^{-1} \mathrm{~d}^{-1}(35,36)$.

We also examined the effects of inosine in the NOD mouse, a genetic model of type 1 diabetes with more in common with the human condition than the chemically induced MLDS model of diabetes (22). Inosine significantly decreased the incidence of diabetes in NOD mice, and this was accompanied by reduced pancreatic islet leukocyte infiltration. The mechanism of action of inosine was similar to that observed in the MLDS model, namely a reduction in pancreatic Th1 cytokine levels with a trend to increased pancreatic levels of Th2 cytokines. Also, inosine reduced
NOD mouse pancreatic levels of MIP-1 $\alpha$, a chemokine responsible for innate and adaptive immune responses because of its ability to recruit, activate, and co-stimulate $\mathrm{T}$ cells and monocytes (37). Similar to data presented here, another study reported increased levels of MIP-1 $\alpha$ in the NOD mouse pancreas and this was correlated with insulitis, whereas removing MIP-1 $\alpha$ either by gene disruption or neutralization using specific antibodies reduced diabetes incidence (38). Interestingly, the reduction of MIP-1 $\alpha$ by inosine appears to be a common observation seen not only in diabetes but also in lipopolysaccharide-induced shock (13), septic shock (14), lung inflammation (15), arthritis, and colitis (9). Increased MIP-1 $\alpha$ levels are pivotal in the pathogenesis of various inflammatory diseases, and inhibiting its production/ expression may, in part, explain why inosine is protective in a wide variety of inflammatory conditions. 

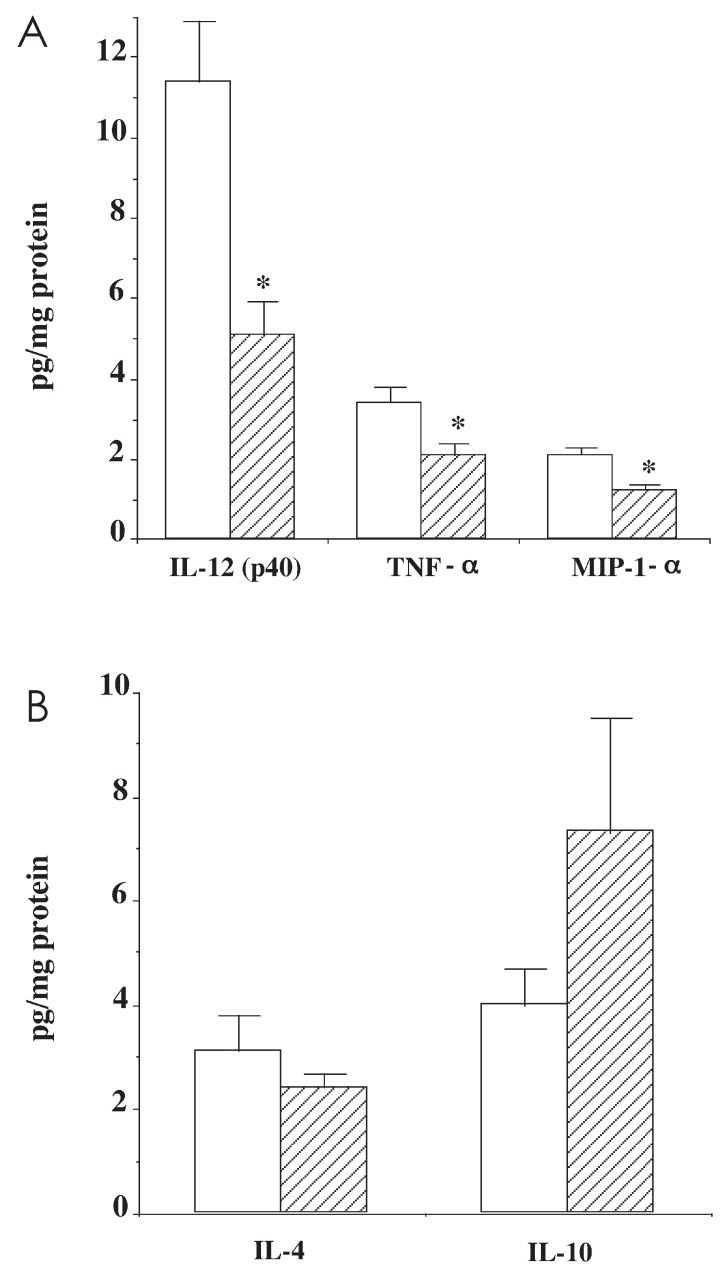

Figure 6. Cytokine and chemokine levels in the pancreata of 18-wk-old normoglycemic female NOD mice treated with either vehicle $(\square)$ or inosine $200 \mathrm{mg} \mathrm{kg}^{-1} \mathrm{~d}^{-1}(\mathrm{Z})$ from $5 \mathrm{wk}$ of age. Inosine significantly reduced levels of IL-12 (p40), TNF- $\alpha$, and MIP-1 $\alpha$ (A); however, no significant effects were observed on levels of IL-4 and IL-10 (B). Results are means \pm SE ( $n=$ 10 mice per group). ${ }^{*} P<0.05$ compared with vehicle-treated mice.

The effects of inosine on inflammatory cytokine and chemokine production were proposed to be mediated, at least in part, by adenosine-receptor related mechanisms (12). Activation of the adenosine $\mathrm{A}_{2 \mathrm{a}}$ receptor has been shown to downregulate inflammation and protect against tissue damage (39). The use of specific inhibitors for this receptor subtype has demonstrated that inosine's inhibitory effect on inflammatory cytokine production is mediated in part by activation of this adenosine receptor (12). It also is possible that inosine produces its inhibitory effects on cytokine production via binding to adenosine $\mathrm{A}_{3}$ receptors shown to be present on monocytes and macrophages (40). However, no specific rodent $A_{3}$ receptor antagonist has been tested so far to investigate this possibility (12). It also is possible that part of the anti-inflammatory effects of inosine are not mediated by adenosine receptor activation but, rather, by other mechanisms (12). The effect of inosine on cytokine release by inflammatory cells is posttranscriptional and does not involve interference with the activation of p38, p42/44 and JNK, degradation of IкB, or elevation of intracellular cAMP levels (12). Recently, it has been established that production of proinflammatory cytokines can be regulated at the translational level. For example, tetracycline (41), metalloproteinase inhibitors (42), and polyamines (43) all suppress the production of inflammatory mediators without affecting transcriptional events. The post-transcriptional nature of inosine's mechanism of action would be preferable to transcriptional inhibitors, because it would be expected to increase the window of therapeutic opportunity, and may remain effective even in a post-treatment paradigm.

Recent data has also indicated that inosine at millimolar concentrations in vitro can inhibit the enzyme, poly (ADP-ribose) polymerase (44), an enzyme implicated in the pathogenesis of various forms of inflammation including autoimmune diabetes $(23,45)$. We do not know whether the concentrations of inosine achieved in this study in vivo reached levels at which a significant inhibition of poly (ADP-ribose) polymerase could have accounted for the protective effects of inosine against diabetes.
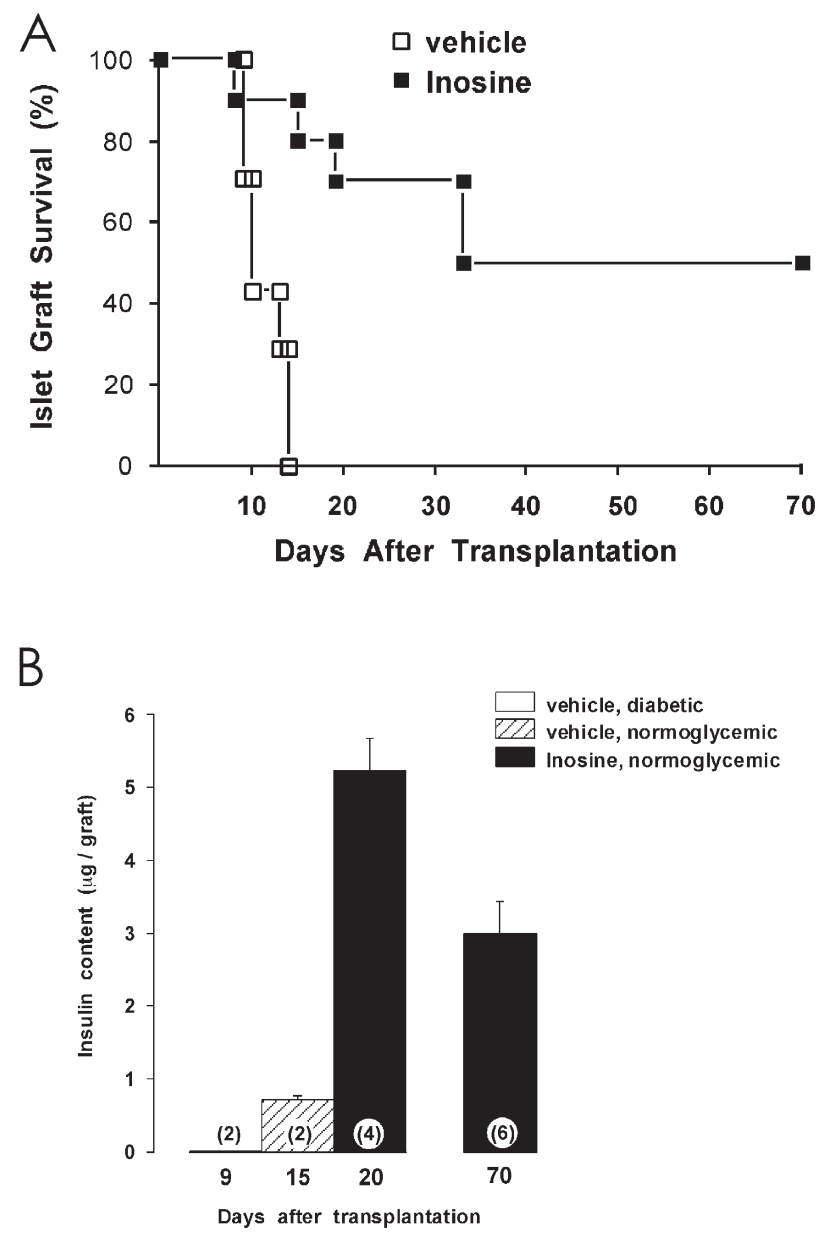

Figure 7. Inosine prolongs survival (A) and insulin content (B) of syngeneic islet grafts transplanted into female diabetic NOD mice. Diabetes recurred in all vehicle-treated ( $\square$ ) mice (7 of 7) by day 14 after islet transplantation, whereas $50 \%$ (5 of 10) mice treated with inosine $200 \mathrm{mg}$ $\mathrm{kg}^{-1} \mathrm{~d}^{-1}(\boldsymbol{\square})$ were normoglycemic at $70 \mathrm{~d}$ after islet transplantation. Grafts from inosine-treated mice which were normoglycemic (ם) had significantly more insulin as compared with vehicle-treated grafts removed from both diabetic ( $\square$ ) and normoglycemic mice ( $\square$ ). 

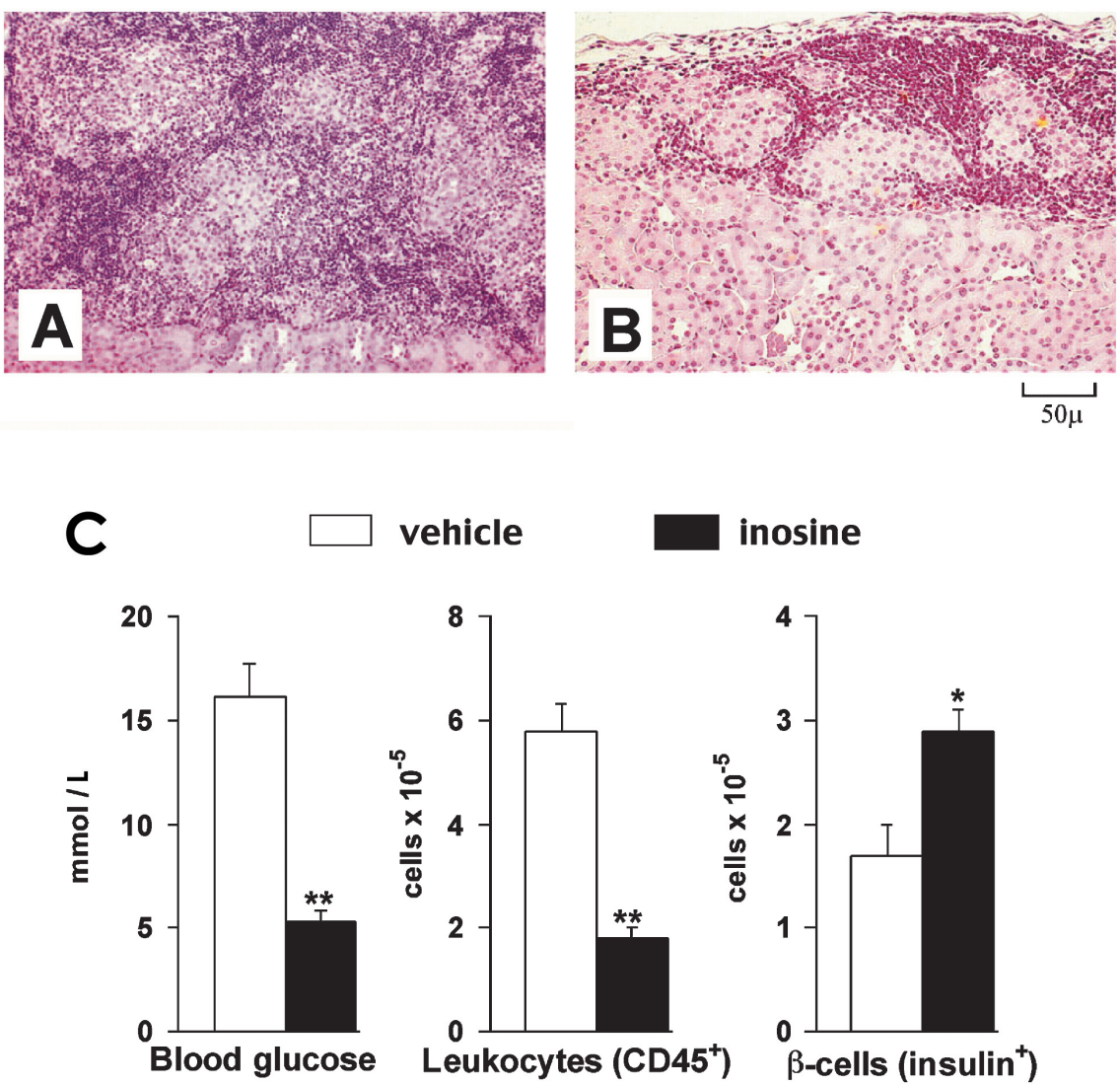

vehicle

inosine
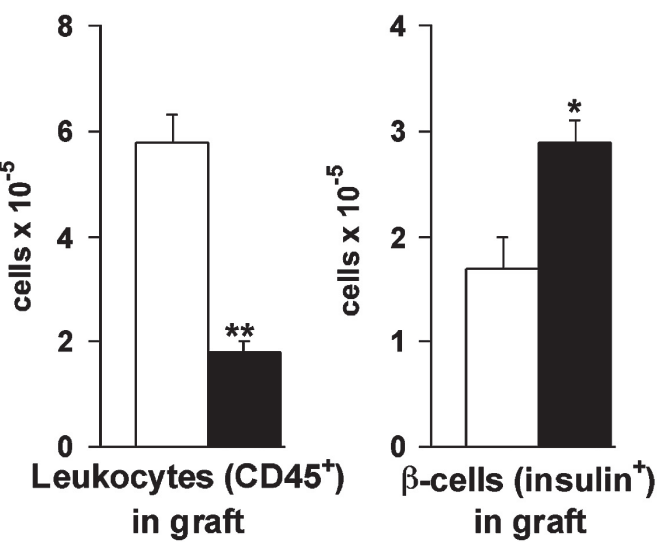

Figure 8. Photomicrographs of islet grafts transplanted under the left renal capsule in diabetic NOD mice treated with vehicle (A) and inosine 200 mg $\mathrm{kg}^{-1} \mathrm{~d}^{-1}(B)$. Grafts were examined 10 to $14 \mathrm{~d}$ after transplantation. Islet graft infiltration by leukocytes is greater in the grafts from vehicle-treated diabetic mice (A) than in inosine-treated normoglycemic mice (B). Inosine-treated mice ( $\mathbf{\square})$ had significantly lower blood glucose levels, fewer CD45 graft-infiltrating leukocytes, and more $\beta$-cells in the grafts than vehicle-treated ( $\square)$ mice $(C)$. Results are means $\pm S E(n=6)$. ${ }^{*} P<0.05 ;{ }^{* *} P<0.01$ compared with vehicle-treated mice.

Transplantation of islets into humans with type 1 diabetes has proved an effective therapy to produce insulin-independence (46), however immunosuppression may be required for life. Therefore, the search for immunosuppressive drugs with minimal side effects is an important endeavor. By using syngeneic islet transplantation in diabetic NOD mice as a model of recurrent autoimmune disease, we found inosine to be an effective therapy. Inosine reduced leukocyte infiltration into the islet graft and maintained the graft insulin content by preventing autoimmune $\beta$-cell destruction resulting in a protection against diabetes recurrence.

Inosine has recently been shown to be more than just an "inactive" metabolite of adenosine, acting not only as an antiinflammatory agent $(9,12-16)$ but also preventing glial cell death during glucose deprivation (47), decreasing the release of intracellular enzymes from hypoxic lymphocytes (48), improving renal function during ischemia (49), removing the harmful effects of total hepatic ischemia (50), and protecting against allergic encephalomyelitis (51).

As described above, the mechanism through which inosine exerts its anti-inflammatory effect is still unclear, and likely to employ multiple mechanisms. An additional mechanism, recently highlighted by studies in murine encephalomyelitis models, may be related to direct antioxidant effects: Inosine is broken down in vivo to produce uric acid, and uric acid has potent antioxidant properties against peroxynitrite and other reactive oxidant species (51). Therefore, at least some of the therapeutic effects, particularly on the inflammatory processes and possibly islet cell damage could be mediated by the antioxidant action of uric acid. In fact, the protective effects of uric acid in a variety of models of inflammation are now well established (52). Future testing of the effect of uric acid in the NOD model of diabetes may directly address this question.

Inosine is a safe, naturally occurring purine, which appears to be nontoxic to humans, even when ingested at high doses (53). Inosine has recently been used in small patient populations for the therapy of multiple sclerosis (54). With an increasing body of preclinical evidence showing that inosine is effective in a wide variety of inflammatory diseases, it may be worthwhile re-evaluating its therapeutic potential in humans suffering from a variety of inflammatory and autoimmune diseases.

\section{ACKNOWLEDGMENTS}

This study was supported by grants from the National Institutes of Health (1R43 DK59676 to GS) and the Canadian Institutes of Health Research (1-199-908 to AR). 
Address correspondence and reprint requests to Jon $G$ Mabley, Inotek Pharmaceuticals Corp, 100 Cummings Center, Suite 419E, Beverly, MA 01915. Phone: 978-232-9660; fax: 978-232-8975; e-mail: jmabley@inotekcorp.com.

Submitted February 13, 2003; accepted for publication May 7, 2003.

\section{REFERENCES}

1. Cronstein BN. (1994) Adenosine, an endogenous anti-inflammatory agent. J. Appl. Physiol. 76:5-13.

2. Apasov S, Koshiba M, Redegeld F, Sitkovsky MV. (1995) Role of extracellular ATP and $\mathrm{P} 1$ and $\mathrm{P} 2$ classes of purinergic receptors in T-cell development and cytotoxic T lymphocyte effector functions. Immunol. Rev. 146:5-19.

3. Hasko G, Szabo C. (1998) Regulation of cytokine and chemokine production by transmitters and co-transmitters of the autonomic nervous system. Biochem. Pharmacol. 56:1079-87.

4. Hasko G, Nemeth ZH, Vizi ES, Salzman AL, Szabo C. (1998) An agonist of adenosine $A 3$ receptors decreases interleukin- 12 and interferon- $\gamma$ production and prevents lethality in endotoxemic mice. Eur. J. Pharmacol. 358:261-8.

5. Szabo C et al. (1998) Suppression of macrophage inflammatory protein (MIP)$1 \alpha$ production and collagen-induced arthritis by adenosine receptor agonists. Br. J. Pharmacol. 125:379-87.

6. Schrier DJ, Lesch ME, Wright CD, Gilbertsen RB. (1990) The antiinflammatory effects of adenosine receptor agonists on the carrageenan-induced pleural inflammatory response in rats. J. Immunol. 145:1874-9.

7. Poelstra K, Heynen ER, Baller JF, Hardonk MJ, Bakker WW. (1992) Modulation of anti-Thyl nephritis in the rat by adenine nucleotides. Evidence for an antiinflammatory role for nucleotidases. Lab. Invest. 66:555-63.

8. Marak Jr GE et al. (1988) Pharmacologic modulation of acute ocular inflammation. I. Adenosine. Ophthalmic Res. 20:220-6.

9. Mabley JG et al. (2003) Inosine reduces inflammation and improves survival in a murine model of colitis. Am. J. Physiol. Gastrointest. Liver Physiol. 284:G138-44.

10. Hasko $G$ et al. (2000) Adenosine inhibits IL-12 and TNF- $\alpha$ production via adenosine A2a receptor-dependent and independent mechanisms. FASEB J. 14:206574.

11. Barankiewicz J, Cohen A. (1985) Purine nucleotide metabolism in resident and activated rat macrophages in vitro. Eur. J. Immunol. 15:627-31.

12. Hasko $G$ et al. (2000) Inosine inhibits inflammatory cytokine production by a posttranscriptional mechanism and protects against endotoxin-induced shock. J. Immunol. 164:1013-9.

13. Garcia Soriano F et al. (2001) Inosine improves gut permeability and vascular reactivity in endotoxic shock. Crit. Care Med. 29:703-8.

14. Liaudet $L$ et al. (2001) Inosine reduces systemic inflammation and improves survival in septic shock induced by cecal ligation and puncture. Am. J. Respir. Crit. Care Med. 164:1213-20.

15. Liaudet $L$ et al. (2002) Inosine exerts a broad range of anti-inflammatory effects in a murine model of acute lung injury. Ann. Surgery 235:568-78.

16. Marton A et al. (2001) Anti-inflammatory effects of inosine in human monocytes, neutrophils and epithelial cells in vitro. Int. J. Mol. Med. 8:617-21.

17. Bach J-F. (1994) Insulin-dependent diabetes mellitus as an autoimmune disease. Endocr. Rev. 15:516-42

18. Rabinovitch A, Suarez-Pinzon WL. (1998) Cytokines and their roles in pancreatic islet $\beta$-cell destruction and insulin-dependent diabetes mellitus. Biochem. Pharmacol. 55:1139-49.

19. Rabinovitch A. (1998) An update on cytokines in the pathogenesis of insulindependent diabetes mellitus. Diabetes Metab. Rev. 14:129-51.

20. Like AA, Rossini AA. (1976) Streptozotocin-induced pancreatic insulitis: new model of diabetes mellitus. Science 193:415-7.

21. Rossini AA, Williams RM, Appel MC, Like AA. (1978) Complete protection from low-dose streptozotocin-induced diabetes in mice. Nature 276:182-4.

22. Atkinson MA, Leiter EH. (1999) The NOD mouse model of type 1 diabetes: as good as it gets? Nat. Med. 5:601-4.

23. Mabley JG et al. (2001) Inhibition of poly (ADP-ribose) synthetase by gene disruption or inhibition with 5-iodo-6-amino-1,2-benzopyrone protects mice from multiple-low-dose-streptozotocin-induced diabetes. Br. J. Pharmacol. 133:90919

24. Chatenoud L, Primo J, Bach JF. (1997) CD3 antibody-induced dominant self tolerance in overtly diabetic NOD mice. J. Immunol. 158:2947-54

25. Ryu S, Kodama S, Ryu K, Schoenfeld DA, Faustman DL. (2001) Reversal of established autoimmune diabetes by restoration of endogenous beta cell function. J. Clin. Invest. 108:63-72.

26. Bradford MM. (1976) A rapid and sensitive method for the quantification of microgram quantities of protein utilizing the principle of protein-dye binding. Anal. Biochem. 72:248-54

27. Mabley JG, Virag L, Szabo C. (2002) Role of poly (ADP-ribose) polymerase activation in the pathogenesis of diabetes mellitus and diabetic vascular dysfunction. In: PARP as a therapeutic target. Zhang J (ed.) CRC Press, London, pp. 277 319

28. Gotoh M, Maki T, Kiyoizumi T, Satomi S, Monaco AP. (1985) An improved method for isolation of mouse pancreatic islets. Transplantation 40:437-8.

29. Wang T, Singh B, Warnock GL, Rajotte RV. (1992) Prevention of recurrence of IDDM in islet-transplanted diabetic NOD mice by adjuvant immunotherapy. Diabetes 41:114-7.

30. Suarez-Pinzon WL, Mabley JG, Strynadka K, Power RF, Szabo C, Rabinovitch A (2001) An inhibitor of inducible nitric oxide synthase and scavenger of peroxynitrite prevents diabetes development in nod mice. J. Autoimmun. 16:449-55.

31. Eizirik DL, Darville MI. (2001) $\beta$-cell apoptosis and defense mechanisms: lessons from type 1 diabetes. Diabetes 50 Suppl 1:S64-9.

32. Rabinovitch A, Suarez-Pinzon WL, Sorensen O. (1996) Interleukin 12 mRNA expression in islets correlates with $\beta$-cell destruction in NOD mice. J. Autoimmun. 9:645-51.

33. Rothe H, O'Hara Jr RM, Martin S, Kolb H. (1997) Suppression of cyclophosphamide induced diabetes development and pancreatic Th1 reactivity in NOD mice treated with the interleukin (IL)-12 antagonist IL-12(p40)2. Diabetologia 40:641-6.

34. Kolb H et al. (1987) Analysis of 22 immunomodulatory substances for efficacy in low-dose streptozotocin-induced diabetes. Diabetes Res. 6:21-7.

35. Wybran J, Famaey JP, Appelboom T. (1981) Inosiplex: a novel treatment in rheumatoid arthritis? J. Rheumatol 8:643-6.

36. Campoli-Richards DM, Sorkin EM, Heel RC. (1986) Inosine pranobex. A preliminary review of its pharmacodynamic and pharmacokinetic properties, and therapeutic efficacy. Drugs 32:383-424.

37. Ward SG, Bacon K, Westwick J. (1998) Chemokines and T lymphocytes: more than an attraction. Immunity $9: 1-11$.

38. Cameron MJ et al. (2000) Differential expression of CC chemokines and the CCR5 receptor in the pancreas is associated with progression to type I diabetes. J. Immunol. 165:1102-10.

39. Ohta A, Sitkovsky M. (2001) Role of G-protein-coupled adenosine receptors in downregulation of inflammation and protection from tissue damage. Nature 414:916-20.

40. McWhinney CD et al. (1996) Activation of adenosine A3 receptors on macrophages inhibits tumor necrosis factor- $\alpha$. Eur. J. Pharmacol. 310:209-16.

41. Shapira L, Houri Y, Barak V, Soskolne WA, Halabi A, Stabholz A. (1997) Tetracycline inhibits Porphyromonas gingivalis lipopolysaccharide-induced lesions in vivo and TNF- $\alpha$ processing in vitro. J. Periodontal Res. 32:183-8.

42. Mohler KM et al. (1994) Protection against a lethal dose of endotoxin by an inhibitor of tumour necrosis factor processing. Nature 370:218-20.

43. Zhang $M$ et al. (1997) Spermine inhibits proinflammatory cytokine synthesis in human mononuclear cells: a counterregulatory mechanism that restrains the immune response. J. Exp. Med. 185:1759-68.

44. Virag L, Szabo C. (2001) Purines inhibit poly(ADP-ribose) polymerase activation and modulate oxidant-induced cell death. FASEB J 15:99-107.

45. Mabley JG et al. (2001) Anti-inflammatory effects of a novel, potent inhibitor of poly (ADP-ribose) polymerase. Inflamm. Res. 50:561-9.

46. Ryan EA et al. (2001) Clinical outcomes and insulin secretion after islet transplantation with the Edmonton protocol. Diabetes 50:710-9.

47. Jurkowitz MS, Litsky ML, Browning MJ, Hohl CM. (1998) Adenosine, inosine, and guanosine protect glial cells during glucose deprivation and mitochondrial inhibition: correlation between protection and ATP preservation. J. Neurochem. 71: 535-48.

48. Cole AW, Palmer TN. (1979) Action of purine nucleosides on the release of intracellular enzymes from rat lymphocytes. Clin. Chim. Acta. 92:93-100.

49. de Rougemont D, Brunner FP, Torhorst J, Wunderlich PF, Thiel G. (1982) Superficia nephron obstruction and medullary congestion after ischemic injury: effect of protective treatments. Nephron 31:310-20.

50. Tilser I, Martinkova J, Chladek J. (1993) The effect of metipranolol and inosine on total hepatic ischemia of rats in vivo. Sb Ved Pr Lek Fak Karlovy Univerzity Hradci Kralove 36:25-9.

51. Scott GS, Spitsin SV, Kean RB, Mikheeva T, Koprowski H, Hooper DC. (2002) Therapeutic intervention in experimental allergic encephalomyelitis by admin istration of uric acid precursors. Proc. Natl. Acad. Sci. U.S.A. 99:16303-8.

52. Scott GS, Hooper DC. (2001). The role of uric acid in protection against peroxynitrite-mediated pathology. Med. Hypotheses. 56:95-100.

53. Williams $\mathrm{MH}$ et al. (1990) Effect of inosine supplementation on 3-mile treadmil run performance and VO2 peak. Med. Sci. Sports Exerc. 22:517-22.

54. Spitsin S et al. (2001) Inactivation of peroxynitrite in multiple sclerosis patients after oral administration of inosine may suggest possible approaches to therapy of the disease. Mult. Scler. 7:313-9. 